\title{
Environmental impacts of COVID-19 on Victoria, Australia, witnessed two waves of Coronavirus
}

\author{
Mahdi Boroujeni $^{1} \cdot$ Mohammad Saberian $^{1} \cdot$ Jie $^{\mathbf{L i}^{1}}$ \\ Received: 30 November 2020 / Accepted: 14 January 2021 / Published online: 28 January 2021 \\ (C) The Author(s), under exclusive licence to Springer-Verlag GmbH, DE part of Springer Nature 2021
}

\begin{abstract}
The COVID-19 pandemic not only has created a global health crisis but also has dramatic effects on the environment. To fight the spread of Coronavirus, governments imposed social distancing policies, which caused negative and positive impacts on the environment. Victoria, the second-most populated state in Australia, was hit by two waves of COVID-19. During the second wave of the pandemic, Victoria, especially Melbourne, experienced one of the most stringent and longest lockdowns globally. In this study, the changes in mobility trends, traffic, air pollution, noise pollution, and waste generation during the first and second waves of COVID-19 in Victoria are evaluated and compared. It was observed that the pandemic had both positive and negative impacts on the environment. During the second wave of the pandemic in Victoria, the mobility trends of public transport hubs, retail and recreation venues, and workplaces experienced a significant drop in movements at respective values of $85 \%, 83 \%$, and $76 \%$ compared to the period of 5 weeks from 3 January to 6 February $2020 . \mathrm{PM}_{2.5}$ levels were lower by $23 \%$ at Alphington and $24 \%$ at Footscray from 16 March to 1 May 2020 compared with the average $\mathrm{PM}_{2.5}$ levels in the past 4 years. It was estimated that the respective daily generations of used face masks during the first wave and second wave of the pandemic in Victoria were approximately 104 and 160 tons.
\end{abstract}

Keywords COVID-19 $\cdot$ Pandemic $\cdot$ Environmental impacts $\cdot$ Waste generation $\cdot$ Victoria $\cdot$ Melbourne

\section{Introduction}

The new Coronavirus (SARS-CoV2) has caused many problems around the world and impacted almost all countries. The virus has spread to more than 83.9 million people and caused about 1.8 million deaths (WHO, 2020). Currently, several countries are dealing with the second or third wave of the virus with far worse effects than the first wave.

The COVID-19 pandemic has also affected the environment directly and indirectly. For example, because of the social distancing and curfew policies, it has been predicted that the greenhouse gas emissions could reduce to levels never before been observed since the Second World War (Zambrano-Monserrate et al., 2020). Considerable reductions

Responsible Editor: Lotfi Aleya

Mohammad Saberian

mohammad.boroujeni@ rmit.edu.au

1 School of Engineering, RMIT University, Melbourne, Victoria, Australia in nitrogen dioxide concentrations and PM 2.5 levels were observed in major cities of China because of the shutdown of some industrial facilities and power plants, the curfew, and strong social distancing measures (Jiang et al., 2021). Similarly, it has been reported that air pollution has significantly reduced in Europe (Giani et al., 2020). According to UNCTAD (2020), the global Coronavirus lockdown led to a $5 \%$ decrease in greenhouse gas emissions in the first half of 2020 compared to the same period in 2019. Liu et al. (2020) reported that global $\mathrm{CO}_{2}$ emissions reduced by approximately $8.8 \%$ for the same period.

Although the pandemic has had some indirect and shortterm positive environmental impacts, it caused more severe adverse effects on solid waste management and plastic production. Unfortunately, the COVID-19 pandemic has hit the municipal solid waste management in many countries (Daryabeigi Zand and Vaezi Heir, 2020). For instance, due to the concerns about the spread of the virus, some states in the USA temporarily closed recycling centres, suspended curbside recycling pickup, and onboard recyclables collections (Staub, 2020). Similarly, in some European countries, the sorting of household wastes has been prohibited. To fight 
the spread of the virus, a huge surge in demand for plasticbased products has been observed, and some policies on plastic production and plastic bag bans have been suspended. This is simply because of (1) the demand for personal protective equipment (PPE) in the healthcare system and community, (2) the recommended or mandatory face mask use policies around the world, and (3) the generation of typical packaging plastic waste because of the significant increase in online shopping and home delivery services (Sharma et al., 2020). Moreover, the COVID-19 pandemic has caused huge pressure on the landfills in developing countries, where solid waste materials and hazardous wastes are dumped in poorly managed and open landfills, which can pose health and environmental threats (Rowan and Laffey, 2020).

Victoria is the most densely populated state in Australia, with a population of over 6.68 million. Melbourne, the capital of the State of Victora, is the second-most populated city in Australia, having a population of more than 5 million. Similar to highly populated and large states and provinces around the world, the state of Victoria has not been excluded from the impacts of Coronavirus; however, Australia is among one the most successful countries in managing and controlling the COVID-19 pandemic. The first case of the novel Coronavirus was confirmed in Victoria on 25 January 2020. Then, the first wave of infections in Victoria emerged during the period of early March 2020 to the mid of May (Fig. 1). Victoria's second wave of the COVID-19 spread was mainly caused by the hotel quarantine scandal in Melbourne. Thanks to the efforts of the state's government and the Australian government, and endless efforts of healthcare workers as well as the cooperation and patience of people, the Victorians can now beat the spread of the virus before the situation gets out of control. It is worth to mention that the first restrictions came on 13 March 2020, and on 16 March, new rules came into effect and a state of emergency was declared by the Victorian Government. The second wave, which was 10 times harder than the first wave, could last for more than 5 months. In total, 20,345 confirmed cases and 819 deaths were reported in Victoria by 27 October 2020. By the end of the second wave, the number of confirmed COVID-19 cases in Victoria constitutes about $74 \%$ of the total number of confirmed cases in Australia, while approximately $90 \%$ of the total deaths in Australia occurred in Victoria (Australian Government Department of Health, 2020).

During the second wave of COVID-19, strict social distancing measures and curfew policies were applied by the Victorian Government. In early July, during the stage 3 restrictions, the residents were allowed to leave their homes for only four reasons, including medical care or caregiving, daily exercise, work or school, or purchasing food and supplies. The face-covering rule became mandatory on 22 July. Due to the surge in the number of confirmed cases, more strict rules were introduced in Victoria from the beginning of August until the end of October. The rules included curfew from $8 \mathrm{pm}$ to $5 \mathrm{am}$, leaving home for shopping within $5 \mathrm{~km}$ from home, 1-hour limitation of exercise per day within $5 \mathrm{~km}$, schools returned to remote learning, public transport services reduced, closing of many stores, shops, and retails, etc. The curfew and most of the strict rules were lifted after cases of Coronavirus were eliminated on 27 October 2020. One hundred eleven days of lockdown ranks among the toughest in the world. However, some rules, such as the mandatory face mask use in the whole of Victoria, are still in place. Consequently, all of the rules and strict policies during the lockdowns had effects on the environment of Victoria, primarily the metropolitan Melbourne.

Previous studies mainly focused on health issues directly related to the SARS-CoV2 Coronavirus. Little attention has been directed to the pandemic's influence on the environment. This paper discusses the negative and positive indirect impacts of COVID-19 on the environment of the State of Victoria, Australia.
Fig. 1 Daily new Coronavirus cases in Victoria from the beginning of the pandemic to the end of the second wave (from the Department of Health and Human Services, 2021)

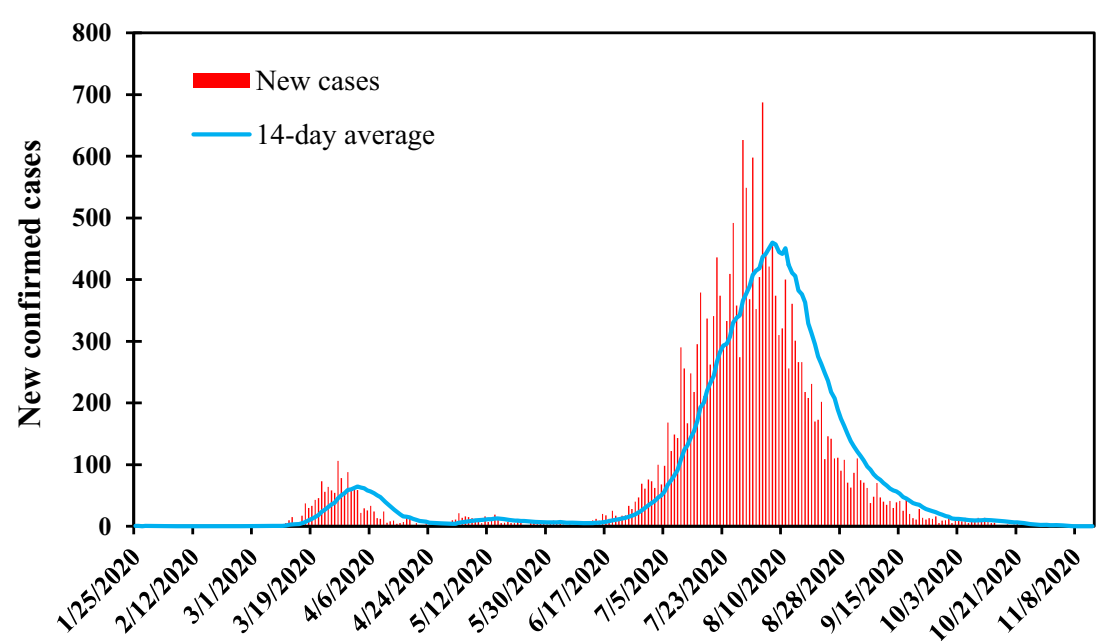


Indirect impacts of COVID-19 on the environment of the State of Victoria

\section{Mobility trends and traffic}

Figure 2 demonstrates the changes in the mobility trends in Victoria and Melbourne City. It can be seen that the mobility trends changed significantly compared to the period before the Coronavirus outbreak in Victoria due to the strict rules during the stage 4 Coronavirus lockdown restrictions in Victoria. Besides, the mobility trends for retail and recreation venues, public transport hubs, and workplaces dramatically reduced, which could be related to the enforced restricting rules, mainly working from homes, staying within $5 \mathrm{~km}$ from homes, and closing of the shops, stores, and retails.

Compared to the mobility trends in the State of Victoria, more significant changes in the mobility trends were observed in Melbourne City. For instance, from 11 September to 23 October 2020, public transport hubs, retail and recreation venues, and workplaces witnessed a considerable reduction in movements at $85 \%, 83 \%$, and $76 \%$, respectively, compared to the baseline, which is the average value of the same day of the week for the period of 5 weeks from 3 January to 6
February 2020. Also, higher reductions in the mobility trends were observed during the second lockdown compared to the first one (Katestone, 2020a). In Melbourne City, residential was the only category that experienced an increase during the pandemic (Google, 2020). The mobility trends for retail and recreation venues, public transport hubs, workplaces, supermarkets and pharmacies, and parks dropped significantly from the beginning of the first wave to the end of the first wave. However, the mobility trends experienced a mild increase between the end of the first wave to the beginning of the second wave. This is mainly because of easing some restrictions between the first and second lockdown periods. During the second lockdown period, mobility trends decreased slightly and remained relatively constant.

During the lockdowns and because of the social distancing restrictions, peak-hour gridlocks in the most common congested areas of Victoria have disappeared. Figure 3 shows the traffic volume change in Melbourne during the pandemic. The traffic in Melbourne dropped significantly during the lockdowns compared to the first 2 weeks of March 2020 (Charting Transport, 2020). An easing of some restrictions after the first wave resulted in an increase in the traffic volume during 25-31 May and the whole of June. A relatively larger
Fig. 2 Mobility changes in a the state of Victoria from 11 September to 23 October 2020 and $\mathbf{b}$ Melbourne City from 7 February 2020 to 23 October 2020 compared with the baseline
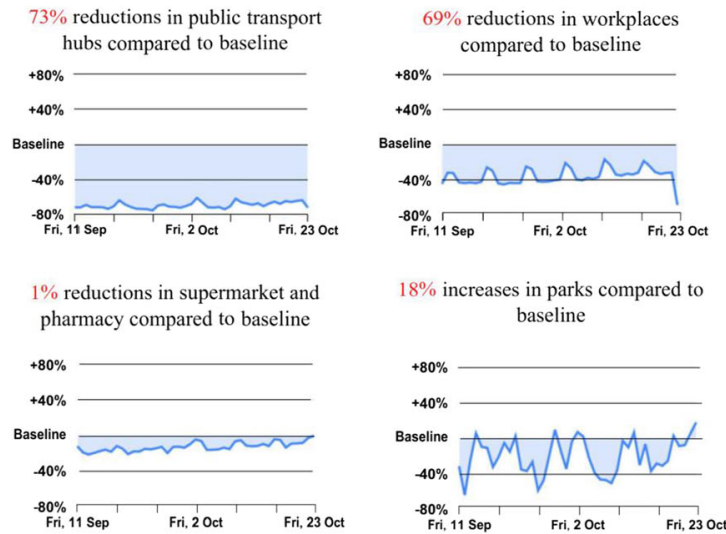

$39 \%$ reductions in retail and recreation venues compared to baseline

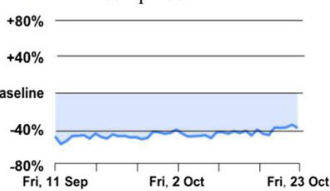

$18 \%$ increases in parks compared to baseline
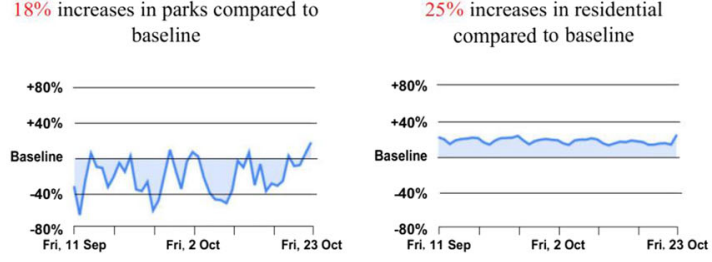

a

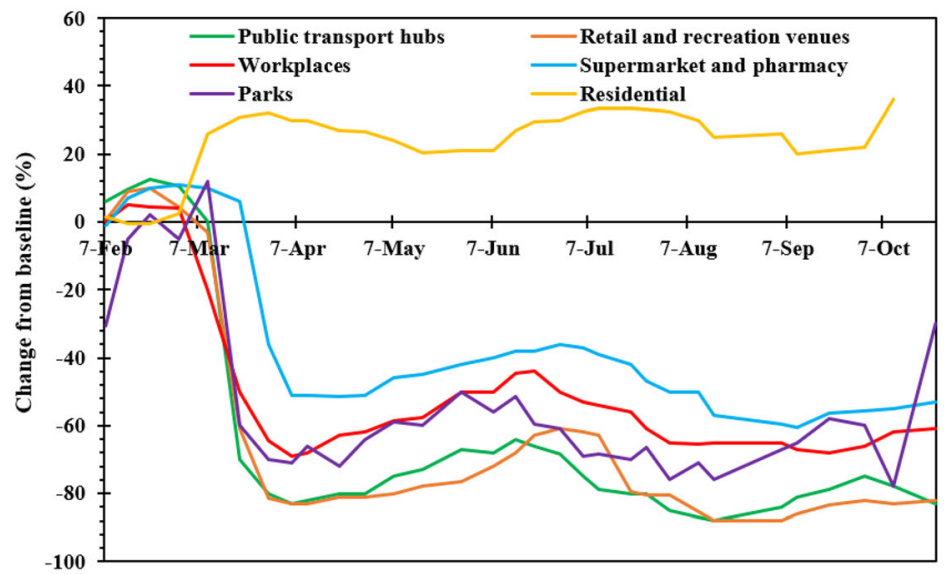

b 


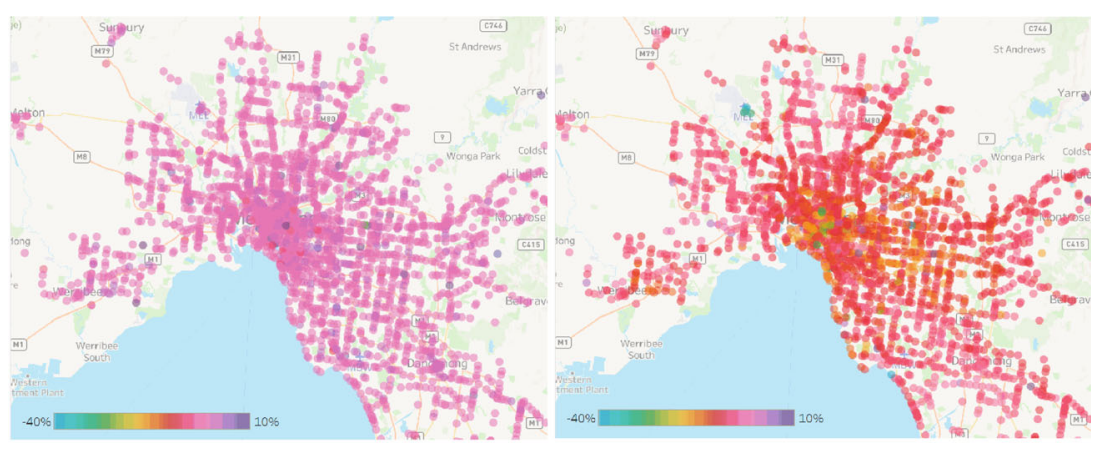

2-8 March

16-22 March

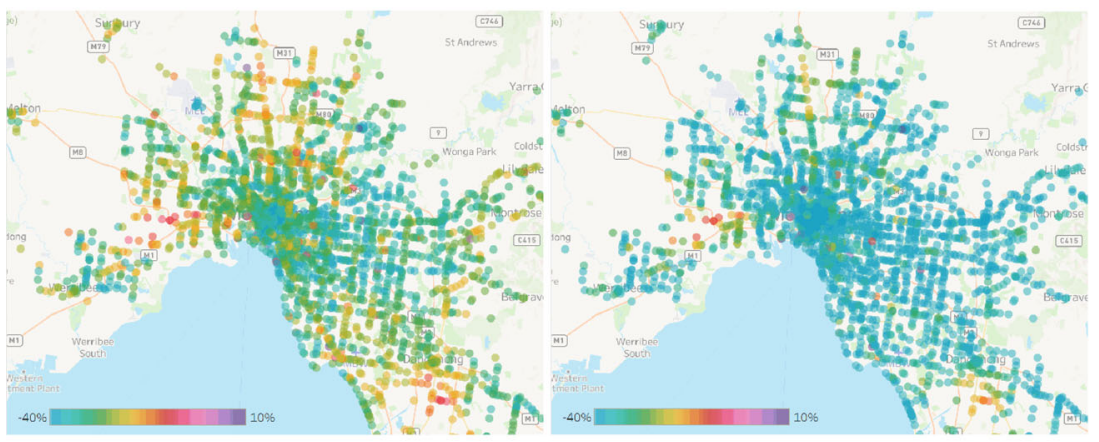

23-29 March

6-12 April

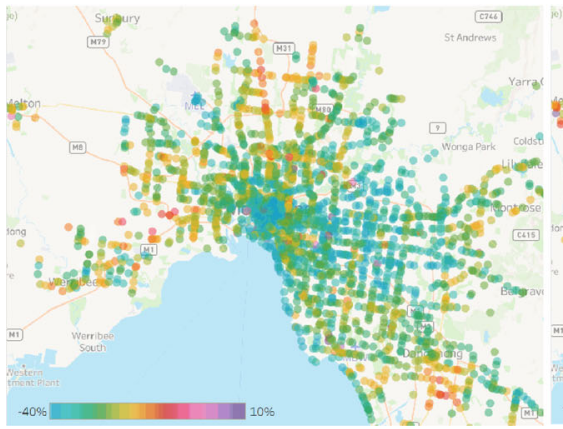

18-24 May

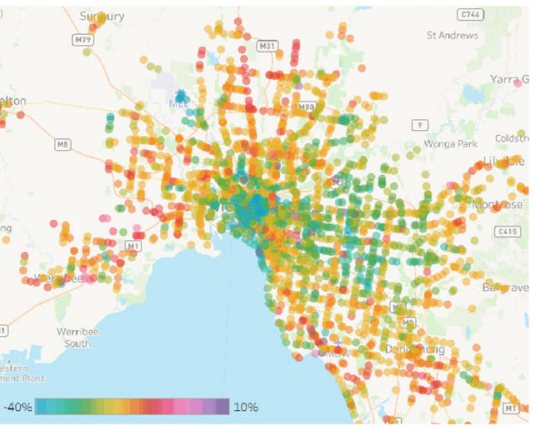

25-31 May

Fig. 3 Traffic change in Melbourne during the pandemic compared to the first 2 weeks of March 2020 (Charting Transport, 2020)

reduction of the traffic volume occurred during the second wave period than the first wave period.

\section{Air pollution}

Air quality affects human health or comfort, but more than $90 \%$ of the world population lives in poor air quality areas. When solid particles, liquids, or gases in the air are sufficient to cause damage to the environment or adversely impact human health, air pollution occurs (Zhang et al., 2017). Salt spray, wind-blown dust, bushfires, industrial activities, and exhaust from motor vehicles are the main reasons of air pollutions. Poor air pollution is responsible for about $8 \%$ of the total deaths in the world (Zambrano-Monserrate et al., 2020).

Figure 4 shows diurnal profiles of $\mathrm{PM}_{2.5}$ and $\mathrm{CO}$ at two sites of Alphington and Footscray in Melbourne and compares the measurements from 16 March to 1 May 2020 with the corresponding period in the past 4 years (2016-2019). On average, $\mathrm{PM}_{2.5}$ levels were observed to be lower by $23 \%$ at Alphington and 24\% at Footscray for 2020 compared with the average $\mathrm{PM}_{2.5}$ levels in the past 4 years. A comparison of the average CO levels revealed that a 39\% reduction occurred at Alphington (Katestone, 2020b,c). In Seoul, Korea, $\mathrm{PM}_{2.5}$ showed a considerable drop of 36\% in March 2020 compared to the same time of 2017-2019 (Seo et al. 2020). A decrease of $20.6 \%$ in $\mathrm{PM}_{2.5}$ levels in the USA was also observed in March 2020 relative to March 2019. Moreover, pollution concentrations reduced by $12.5 \%$ for $\mathrm{CO}$ and $15.4 \%$ for $\mathrm{PM}_{2.5}$ in China from January to March 2020 compared to the same period in 2019 (Liu et al., 2020). A reduction of $28 \%$ to $31 \%$ for $\mathrm{PM}_{10}$ was reported by Tobias et al. (2020) in Barcelona, Spain, during the March lockdown.

On the other hand, it is worthy of evaluating the effects of stage 4 lockdown restrictions in Victoria (started from the 


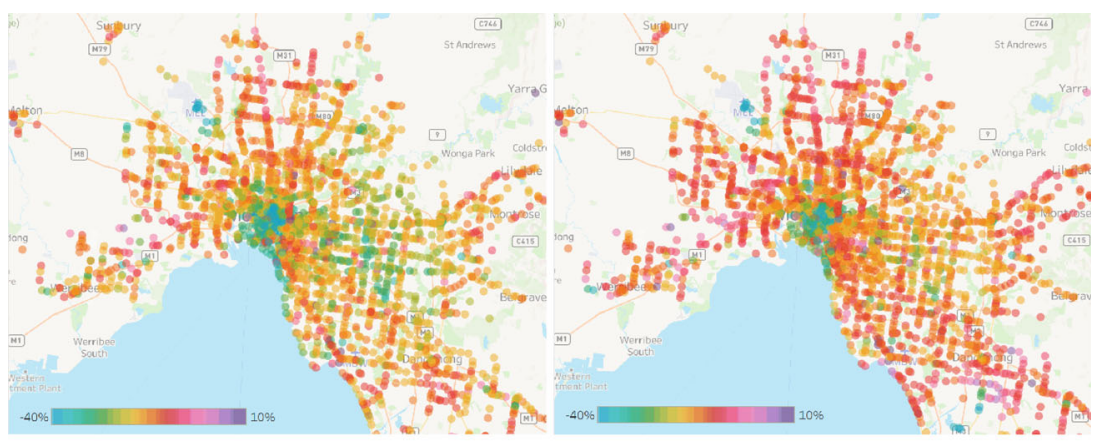

1-7 June

22-28 June

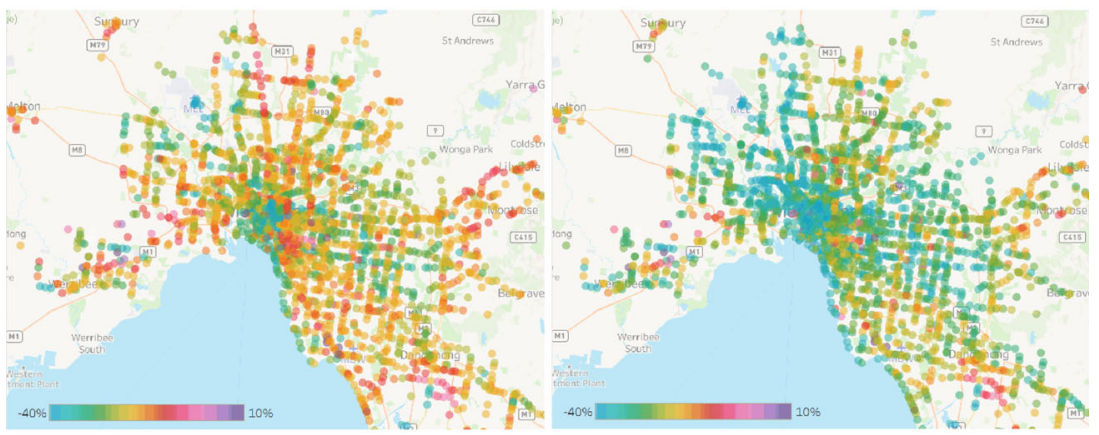

29 June - 5 July

6-12 July

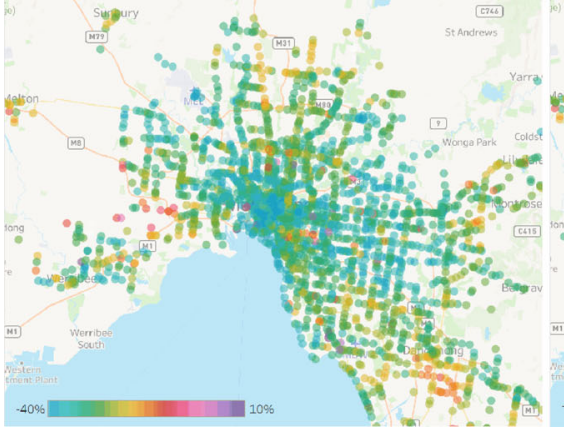

13-19 July

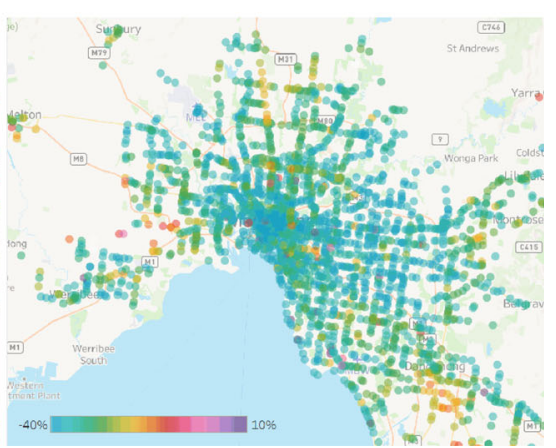

20-26 July

Fig. 3 (continued)

beginning of August 2020) on the air pollution levels. Figure 5 compares the monthly average $\mathrm{NO}_{2}$ concentrations at two sites of Footscray and Alphington in 2020 compared to the monthly average $\mathrm{NO}_{2}$ concentrations in the past 10 years (2010-2019). As can be seen from the figure, from March to April 2020, during the first lockdown, a considerable decrease in $\mathrm{NO}_{2}$ concentrations was observed at both sites compared to the monthly average $\mathrm{NO}_{2}$ concentrations in the past 10 years. This can be attributed to the significant drop in the mobility trends and traffic volumes from March to April 2020, mainly because of the restrictions imposed during the first wave. In fact, the reduction of fossil fuel combustion and industry emissions resulted in a decrease in nitrogen dioxide $\left(\mathrm{NO}_{2}\right)$ emissions. A similar decrease of $\mathrm{NO}_{2}$ was reported for the USA (14.32\%) and China (4.53\%) in March 2020 compared to March 2019 (Liu et al., 2020). A decrease in tropospheric NO2 was also observed in Delhi, India, during the pandemic
(Singh and Chauhan, 2020). Bauwens et al. (2020) reported a considerable decrease of $20-38 \%$ of $\mathrm{NO}_{2}$ in western Europe. During June 2020, the $\mathrm{NO}_{2}$ concentrations returned almost to the average levels, while the $\mathrm{NO}_{2}$ concentrations witnessed an increase in July 2020 compared to the average levels. This is simply because of the easing of some restrictions after the first wave of the pandemic. Due to more strict restrictions, the concentrations of $\mathrm{NO}_{2}$ during the second lockdown reduced significantly compared to the first lockdown and previous years. For instance, in early August 2020, the concentrations of $\mathrm{NO}_{2}$ reduced by $31 \%$ and $38 \%$ at Footscray and Alphington, respectively, compared to July 2020.

\section{Noise pollution}

Environmental noise, which is an unwanted sound, generally generates from industrial, commercial, and construction 
Fig. 4 The concentrations of a $\mathrm{PM}_{2.5}$ and $\mathbf{b} \mathrm{CO}$ in Melbourne from 16 March to 1 May 2020 compared with the corresponding period in the past 4 years (20162019)
Alphington, VIC

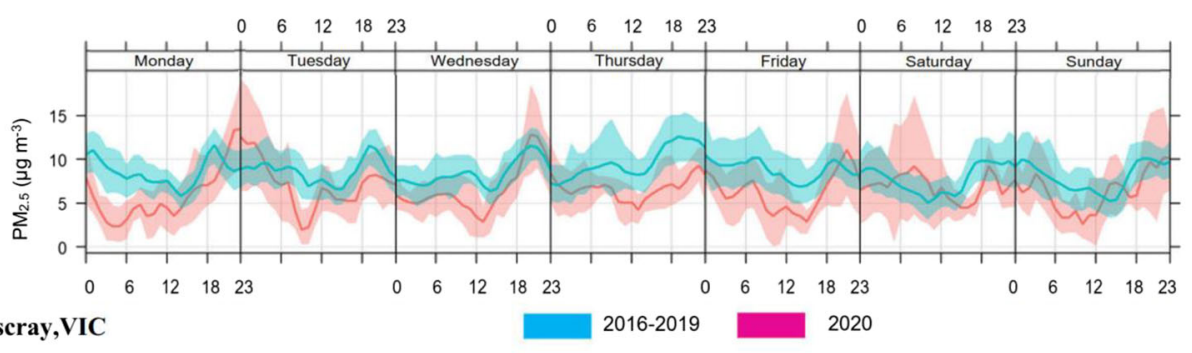

Footscray,VIC

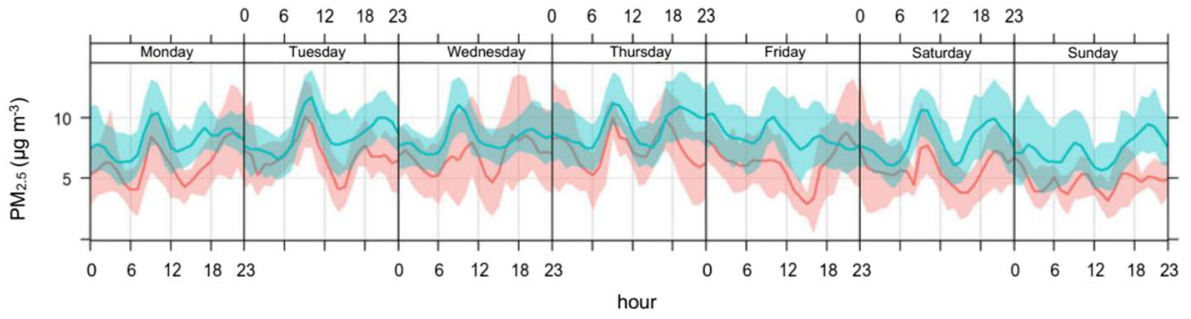

a

Alphington, VIC

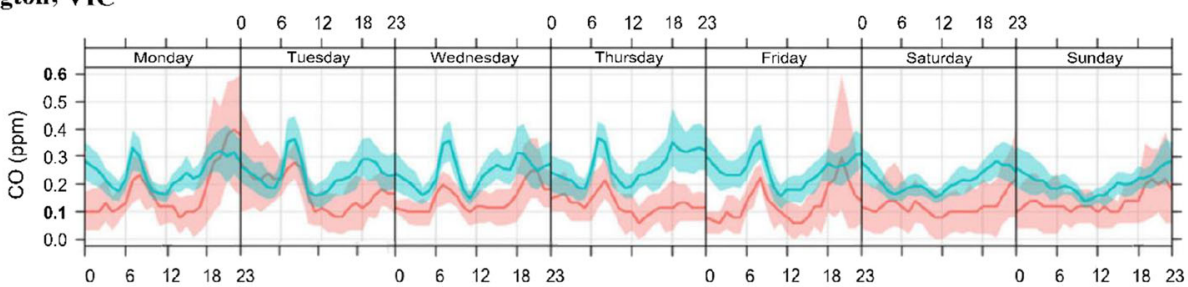

2016-2019

2020

\section{Footscray, VIC}

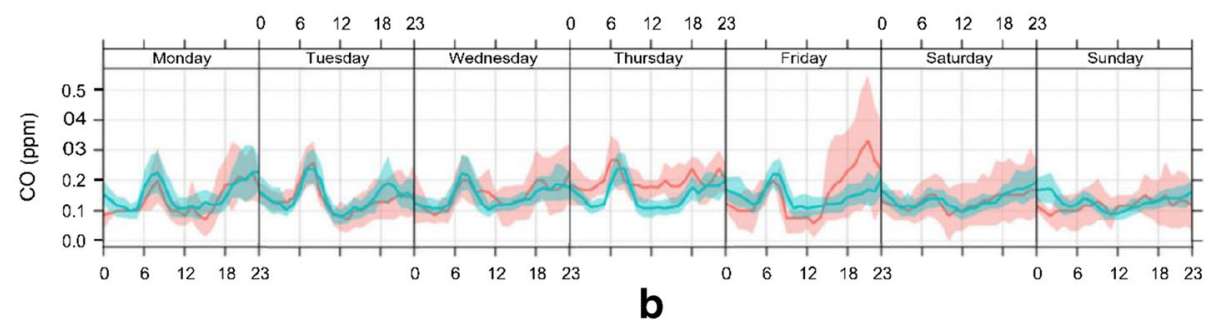

activities, and traffics. Environmental noise pollution may increase the risk of many diseases and change the ecosystem's conditions (Zagubien and Wolniewicz 2021). Lecocq et al. (2020) reported that the COVID-19 restrictions led to significant changes in human activities, which resulted in the longest and most prominent global anthropogenic seismic noise reduction in recorded history and caused a 50\% drop in global median high-frequency seismic ambient noise from March to May 2020.

During the lockdowns in Victoria, imposing the strict social distancing measures and curfew policies enforced people to leave their homes for shopping within specific ranges, returned students to remote learning, and obliged many people to work from home. Compared to the first lockdown period, tougher restrictions during the second lockdown led to a reduction in some public transport services, decreasing the traffic levels, and closure of many retail stores, restaurants, and factories. These changes resulted in a further dropping of environmental noise levels in Victoria and metropolitan Melbourne during the second lockdown period compared to the first lockdown period.

\section{Waste generation}

The COVID-19 pandemic has caused not only health-related issues such as mental health problems, job and economy losses, and socio-economic hardships but also waste management issues in many countries (Acter et al., 2020; Zandifar and Badrfam, 2020). It has put immense pressure on the existing waste collection and management system and caused inappropriate waste management strategies such as local burnings, mobile incinerations, and direct landfills (Adyel, 2020). For instance, Singapore households generated extra 1334 tons of plastic waste in April 2020, which can be attributed to the 

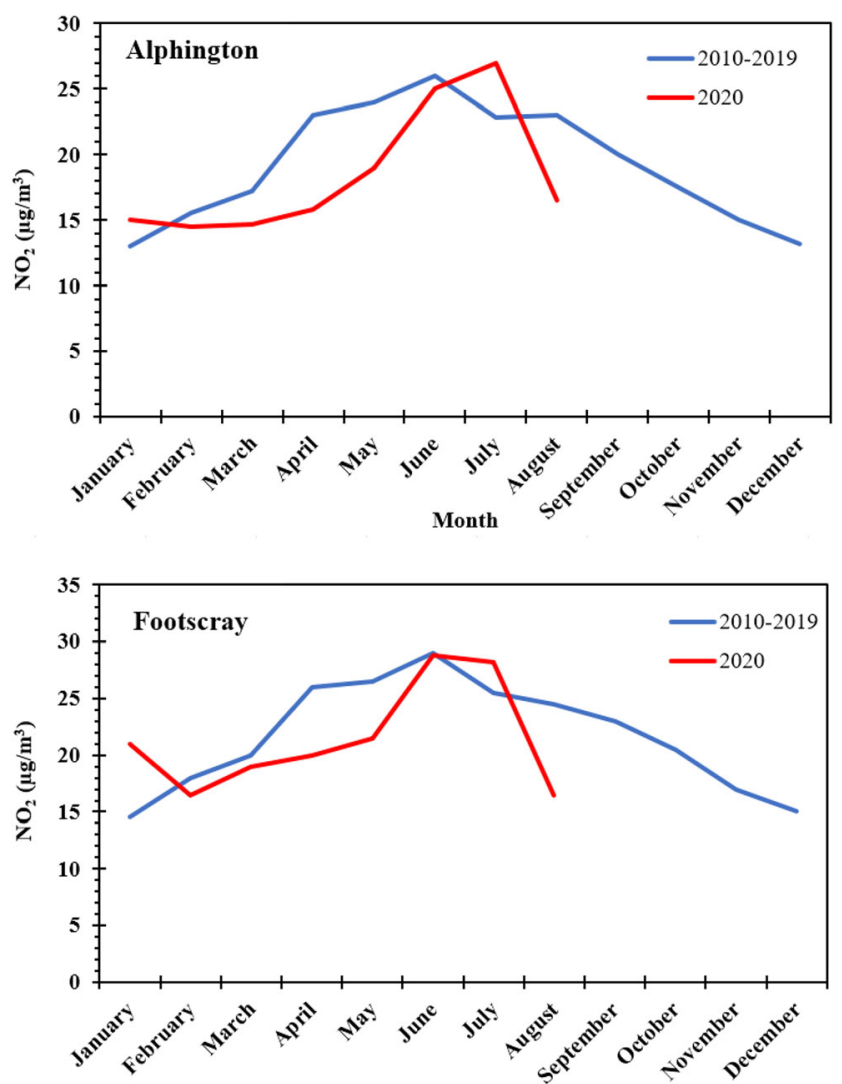

Fig. 5 The monthly average $\mathrm{NO}_{2}$ concentrations at two sites in Melbourne in 2020 compared to the monthly average $\mathrm{NO}_{2}$ concentrations in the past 10 years

change in consumer behaviour during the COVID-19 pandemic. (Fan et al., 2021). During the first lockdown, the City of Melbourne reported a 70\% increase in illegally dumped waste in April 2020, compared with the same period in 2019 (Farrer, 2020). This could be related to the rise in home improvements and renovations, packing waste from shopping online, dumping of unwanted possessions, and used PPE such as gloves and masks.

Although single-use plastic products are banned in many countries, there is a setback in using and management of plastics in the fight with the Coronavirus pandemic (Naughton, 2020). Using PPE is among one of the effective announced guidelines for reducing the spread of the Coronavirus, which resulted in mandatory face mask use in more than half of the countries around the world or recommended face mask use in almost all of the countries (Royo-Bordonada et al., 2020). Consequently, huge amounts of plastic-based PPE, such as masks, gloves, waterproof shoes, protective clothing, face shields, and hand sanitizer bottles and packaging made with polypropylene and polyethylene terephthalate are produced around the world every day. The improper management of plastic-based PPE waste can potentially increase the spread of the virus (Mol and Caldas, 2020). Therefore, to avoid the further spread of the virus, it is crucial to consider the waste management issues of the generation of plastic-based PPE caused by the COVID-19 pandemic (Klemeš et al., 2020).

Wearing a face mask was not mandated in Victoria during the first lockdown but became mandatory on 22 July 2020 (during the second wave of the virus). There is no exact data on the number of face masks used in Victoria. Thus, it is worthy of using the following model proposed by Nzediegwu and Chang (2020) and Sangkham (2020) to estimate the daily face mask use in Victoria, $D_{\mathrm{FM}}$.

$$
D_{\mathrm{FM}}=P \times U_{\mathrm{P}} \times F_{\mathrm{MAR}} \times\left(\frac{F_{\mathrm{MGP}}}{10,000}\right)(1) \text { where } P \text { is the pop- }
$$
ulation of Victoria, which is about $6,689,400$ (Australian Bureau of Statistics, 2020); $U_{\mathrm{P}}$ is the urban population in Victoria, which is about $80 \% ; F_{\mathrm{MAR}}$ is the face masks acceptance rate, which is considered $65 \%$ during the first lockdown and $100 \%$ during the second lockdown in Victoria; and $F_{\text {MGP }}$ is an assumption that how many masks are used by a person in the general population each day, which is considered 1 in this study. Therefore, by using Eq. (1) and the assumptions mentioned above, the daily face mask use in Victoria during the first lockdown and second lockdown can be estimated at $3,478,488$ and 5,351,520, respectively. Taking the average weight of a mask as $30 \mathrm{~g}$, which is the weight of a surgical mask (lowest weight among other masks), it is estimated that about 104 and 160 tonnes of used face masks were generated each day during the first and second wave of the Coronavirus in Victoria, respectively.

As shown in Fig. 6, the used face masks can be spotted everywhere from parks to streets to beaches due to an uptick in littering. Even if they are disposed at a landfill, wind and rainwater can blow or move the lightweight masks into rivers and oceans, and the non-biodegradable plastic-based masks will be fragmented into microplastics (Prata et al., 2020).

\section{Discussion}

A comparison of the traffic and air quality data before and during the lockdowns revealed that the lockdowns improved air quality in Victoria substantially since there were far fewer vehicles on the roads during the lockdowns. The reduction in air pollution can also be attributed to declining industrial/ construction activities and significantly decreasing international flights due to the border closures. Compared to the first lockdown, mobility trends and air pollutants reduced considerably during the second lockdown because of more strict restrictions. The reasons mentioned above also contributed to a substantial reduction of environmental noise pollutions in Victoria and metropolitan Melbourne. It can be seen from the results that after easing of restrictions, mobility trends, air pollution, and traffic shifted to a typical situation before the lockdowns within 1-2 month(s). For instance, during July and August in Melbourne, the air pollution experienced a 
Fig. 6 Discarded used face masks in public spaces in Victoria during the COVID-19 pandemic

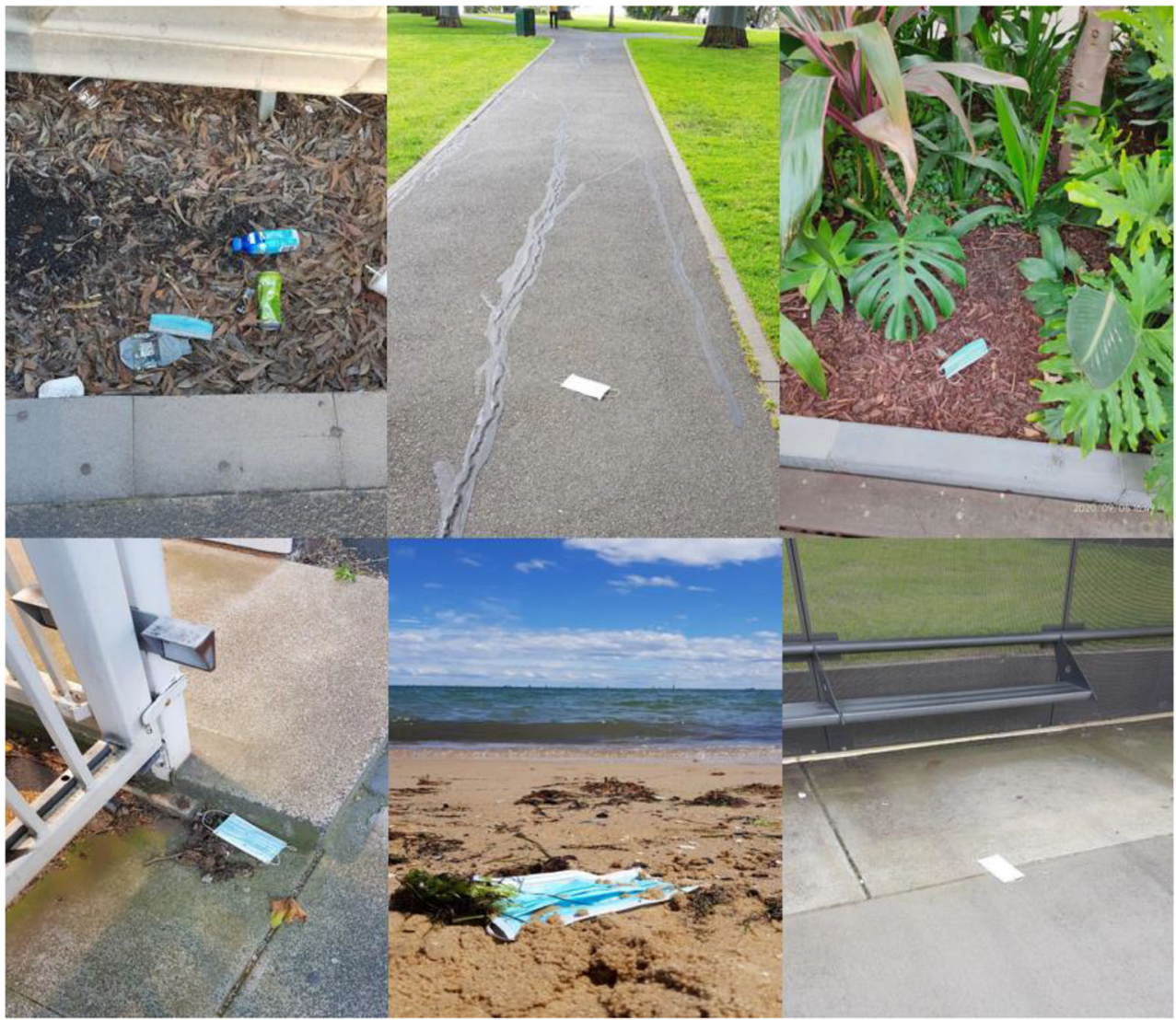

considerable increase even higher than before the pandemic. Therefore, when the pandemic ends, the lockdown-induced positive environmental effects will disappear in a relatively short period. Traffic congestion and air pollution will return to "business as usual". One possible way to reduce traffic for the post-COVID-19 pandemic future is to allow more people to work from home after the Covid-19 crisis.

The social distancing restrictions can lead to higher municipal solid waste generations, as observed in Melbourne, due to increased home renovations, packing waste related to online shopping, and single-use plastic-based items. Furthermore, to control the spread of the virus, a mandated or recommended face mask use policy results in the generation of huge amounts of PPE such as masks and gloves. The improper management of the plastic-based waste results in plastic pollutions and microplastics that cause many environmental issues, such as killing animals and marine life (Fadare and Okoffo, 2020). It is worth to mention that despite the suspended recycling programs in several countries around the world, due to the COVID-19, the planned and ongoing recycling programs in Australia and especially in Victoria have not been stopped. Victorian government and EPA Victoria declared that the facilities of waste and recycling industries remain open during the pandemic, and the industries and councils need to continue to provide waste services to the public (EPA Victoria, 2020).

\section{Conclusions and recommendations}

Based on the comparative study results of the current work, it can be concluded that the COVID-19 pandemic can cause short-term positive impacts on the environment, but the negative effects are more severe. For example, many countries, including Australia, are facing challenges in the waste management of used PPE which are made of non-biodegradable plastics that can take hundreds of years to break down in the environment. According to the estimations of the current study, about 104 and 160 tons of used face masks were generated daily during the first and second wave of the pandemic in Victoria. A noticeable decrease of $85 \%, 83 \%$, and $76 \%$ was observed for the respective mobility trends of public transport hubs, retail and recreation venues, and workplaces during a period of the second wave of the pandemic in Victoria compared to the period of 5 weeks from 3 January to 6 February 2020 (i.e. before the pandemic). Also, PM2.5 levels were lower by $23 \%$ at Alphington and $24 \%$ at Footscray from 16 March to 1 May 2020 compared with the average PM2.5 levels in the past 4 years. But decreasing air pollution, traffic, and noise pollution during lockdowns are not sustainable ways to improve and clean the environment. More importantly, as was observed in the case of Victoria, which experienced the second wave of the pandemic, the positive environmental 
impacts related to COVID-19 can be vanished in a short period after easing of restrictions. Moreover, similar to the much worse situation of the second wave compared to the first wave in terms of the number of cases in most countries, the negative environmental effects of a given wave of the COVID-19 can be harsher and more long-standing than its previous wave. Therefore, all countries need to pay attention to the impacts of the pandemic on the environment as it can cause more and long-lasting environmental problems.

A cross-disciplinary collaborative approach is urgently required to address the current environmental issues caused by the indirect negative impacts of the COVID-19 pandemic. There is a need to reduce the dependency on single-use PPE and reduce pandemic-generated waste. Repurposing the used PPE is an effective way to prevent a large amount of pandemic-generated waste from ending up in the landfill. The authors have already done a feasibility study of using the shredded face mask with recycled concrete aggregate as a road pavement material (Saberian et al. 2021). The results show that building a two-lane 1-km-long road would require approximately 3 million used face masks that would otherwise go to landfill. The feasibility study also found that introducing the used masks to the recycled concrete aggregate can improve the strength, ductility, and flexibility of pavements base/subbase. To keep air and noise pollution at low levels, local governments and policymakers should implement emissions and vehicle efficiency standards, encouraging consumers to use electric vehicles that produce no carbon dioxide emissions and less noise compared to conventional vehicles.

This paper presents preliminary findings based on the limited data available. More studies, particularly a large-scale national or cross-national (regional/international) assessment, are required to fully understand the impact of the COVID-19 pandemic on the environment.

Acknowledgements The authors gratefully acknowledge the help of experts at Katestone.

Authors' contributions Mahdi Boroujeni: methodology, validation, investigation, writing - original draft, data curation, formal analysis, visualization. Mohammad Saberian: methodology, validation, investigation, writing - original draft, data curation, formal analysis, visualization. Jie Li: writing - review and editing, supervision, resources, validation, supervision, project administration, conceptualization. All authors contributed to the research article and approved the final version.

Data availability Not applicable.

\section{Compliance with ethical standardsEthical approval Not applicable.}

Consent to participate Not applicable.

Consent to publish Not applicable.
Competing interests The authors declare that they have no conflict of interest.

\section{References}

Acter T, Uddin N, Das J, Akhter A, Choudhury TR, Kim S (2020) Evolution of severe acute respiratory syndrome coronavirus 2 (SARS-CoV-2) as coronavirus disease 2019 (COVID-19) pandemic: a global health emergency. Sci Total Environ 730:138996

Australian Bureau of Statistics, (2020). National, state and territory population. https://www.abs.gov.au/statistics/people/population/ national-state-and-territory-population/latest-release. Accessed date: 30 October 2020.

Australian Government Department of Health, (2020). Coronavirus (COVID-19) at a glance infographic collection. https://www. health.gov.au/resources/collections/coronavirus-covid-19-at-aglance-infographic-collection. Accessed date: 05 January 2021.

Adyel TM (2020) Accumulation of plastic waste during COVID-19. Science 369(6509):1314-1315 Accessed date: 14 November 2020.

Bauwens, M., Compernolle, S., Stavrakou, T., Muller, J.F., van Gent, J., Eskes, H., Levelt, P.F., Van Der, A.R., Veefkind, J.P., Vlietinck, J., $\mathrm{Yu}, \mathrm{H}$., Zehner, C., (2020). Impact of coronavirus outbreak on $\mathrm{NO}_{2}$ pollution assessed using TROPOMI and OMI observations. Geophys Res Lett, 47, e2020GL087978.

Charting Transport, (2020). What impact has the 2020 COVID-19 pandemic had on road traffic volumes in Victoria? https:// chartingtransport.com/category/road-traffic/.

Daryabeigi Zand A, Vaezi Heir A (2020) Emerging challenges in urban waste management in Tehran, Iran during the COVID-19 pandemic. Resour Conserv Recycl 162:105051

Department of Health and Human Services, (2021). Victorian coronavirus (COVID-19) data. https://www.dhhs.vic.gov.au/victoriancoronavirus-covid-19-data. Accessed date: 05 January 2020.

Fadare OO, Okoffo ED (2020) Covid-19 face masks: a potential source of microplastic fibers in the environment. Sci Total Environ 737: 140279

Fan YV, Jiang P, Hemzal M, Klemeš JJ (2021) An update of COVID-19 influence on waste management. Sci Total Environ 754:142014

Farrer, M., (2020). Australian councils struggle with huge rise in household rubbish during Covid-19 lockdown. The Guardian. https:// www.theguardian.com/australia-news/2020/jun/03/australiancouncils-struggle-with-huge-rise-in-household-rubbish-duringcovid-19-lockdown. Accessed date: 05 January 2021.

Giani P, Castruccio S, Anav A, Howard D, Hu W, Crippa P (2020) Shortterm and long-term health impacts of air pollution reductions from COVID-19 lockdowns in China and Europe: a modelling study. Lancet Planetary Health 4(10):e474-e482

Google, (2020). COVID-19 community mobility report. AU Victoria Mobility Report. https://www.gstatic.com/covid19/mobility/202010-23_AU_Victoria_Mobility_Report_en-GB.pdf. Accessed date: 14 November 2020.

Jiang P, Fu X, Fan YV, Klemeš JJ, Chen P, Ma S, Zhang W (2021) Spatial-temporal potential exposure risk analytics and urban sustainability impacts related to COVID-19 mitigation: a perspective from car mobility behaviour. J Clean Prod 279:123673

Katestone, (2020a). A Second Wave? An update on the Australian Air Quality after COVID-19 mobility restriction measures. https:// katestone.global/air-quality-covid-19-update3/. Accessed date: 05 January 2021.

Katestone, (2020b). CO, $\mathrm{PM}_{2.5}$ and $\mathrm{NO}_{2}$ : which air pollutant best illustrates the effect of COVID-19 mobility restrictions on air quality. https://katestone.global/air-quality-covid-19-update2/. Accessed date: 05 January 2021. 
Katestone, (2020c). Update on the Australian Air Quality after the implementation of the COVID-19 mobility restrictions. https://katestone. global/air-quality-covid-19-update1/.

Klemeš JJ, Fan YV, Tan RR, Jiang P (2020) Minimising the present and future plastic waste, energy and environmental footprints related to COVID-19. Renew Sust Energ Rev 127:109883

Lecocq T, Hicks SP, Noten KV et al (2020) Global quieting of highfrequency seismic noise due to COVID-19 pandemic lockdown measures. Science 369(6509):1338-1343

Liu Z, Ciais P, Deng Z, Lei R, Davis SJ, Feng S, Zheng B, Cui D, Dou X, Zhu B, Guo R, Ke P, Sun T, Lu C, He P, Wang Y, Yue X, Wang Y, Lei Y, Zhou H, Cai Z, Wu Y, Guo R, Han T, Xue J, Boucher O, Boucher E, Chevallier F, Tanaka K, Wei Y, Zhong H, Kang C, Zhang N, Chen B, Xi F, Liu M, Bréon FM, Lu Y, Zhang Q, Guan D, Gong P, Kammen DM, He K, Schellnhuber HJ (2020) Near-realtime monitoring of global $\mathrm{CO}_{2}$ emissions reveals the effects of the COVID-19 pandemic. Nat Commun 11:5172

Mol MPG, Caldas S (2020) Can the human coronavirus epidemic also spread through solid waste? Waste Manag Res 38(5):485-486

Naughton CC (2020) Will the COVID-19 pandemic change waste generation and composition?: the need for more real-time waste management data and systems thinking. Resour Conserv Recycl 162: 105050

Nzediegwu C, Chang SX (2020) Improper solid waste management increases potential for COVID-19 spread in developing countries. Resour Conserv Recycl 161:104947

Prata JC, Patrício Silva AL, Walker TR, Duarte AC, Rocha Santos T (2020) COVID-19 pandemic repercussions on the use and management of plastics. Environ Sci Technol 54(13):7760-7765

Rowan NJ, Laffey JG (2020) Unlocking the surge in demand for personal and protective equipment (PPE) and improvised face coverings arising from coronavirus disease (COVID-19) pandemic - implications for efficacy, re-use and sustainable waste management. Sci Total Environ 752:142259

Royo-Bordonada, M.A., García-López, F.J., Cortés, F., Andrés Zaragoza, G., (2020). Face masks in the general healthy population. Scientific and ethical issuesMascarillas en población general sana Cuestiones científicas y éticas Gaceta Sanitaria, 1-5.

Saberian M, Li J, Kilmartin-Lynch S, Boroujeni M (2021) Repurposing of COVID-19 single-use face masks for pavements base/subbase. Sci Total Environ
Sangkham S (2020) Face mask and medical waste disposal during the novel COVID-19 pandemic in asia. Case Stud Chem Environ Eng 2: 100052

Sharma HB, Vanapalli KR, Cheela VRS, Ranjan VP, Jaglan AK, Dubey B, Goel S, Bhattacharya J (2020) Challenges, opportunities, and innovations for effective solid waste management during and post COVID-19 pandemic. Resour Conserv Recycl 162:105052

Seo JH, Jeon HW, Sung UJ, Sohn JR (2020) Impact of the COVID-19 outbreak on air quality in Korea. Atmosphere 11:1137

Singh RP, Chauhan A (2020) Impact of lockdown on air quality in India during COVID-19 pandemic. Air Qual Atmos Health 13:921-928

Staub, C., (2020). Coronavirus pandemic disrupts recycling sector. Resour Recycl https://resource-recycling.com/recycling/2020/03/ 17/coronavirus-pandemic-disrupts-recycling-sector/. Accessed date: 05 January 2021.

Tobias A, Carnerero C, Reche C, Massagué J, Via M, Minguillon MC, Alastuey A, Querol X (2020) Changes in air quality during the lockdown in Barcelona (Spain) one month into the SARS-CoV-2 epidemic. Sci Total Environ 726:138540

UNCTAD, (2020). COVID-19 stalls progress on Global Goals. https:// unctad.org/news/covid-19-stalls-progress-global-goals. .

WHO, (2020). https://www.who.int/emergencies/diseases/novelcoronavirus-2019. .

Zagubień A, Wolniewicz K (2021) Impact of measuring microphone location on the result of environmental noise assessment. Appl Acoust 172:107662

Zambrano-Monserrate MA, Ruano MA, Sanchez-Alcalde L (2020) Indirect effects of COVID-19 on the environment. Sci Total Environ 728:138813

Zandifar A, Badrfam R (2020) Iranian mental health during the COVID19 epidemic. Asian J Psychiatr 51:101990

Zhang Q, Jiang X, Tong D, Davis SJ, Zhao H, Geng G, Ni R (2017) Transboundary health impacts of transported global air pollution and international trade. Nature 543:705-709

Publisher's note Springer Nature remains neutral with regard to jurisdictional claims in published maps and institutional affiliations. 